\title{
EFFECT OF MAGNETIC-PULSED TREATMENT OF FILLER MATERIALS ON DEPOSITED METAL STRUCTURE
}

Yu.M. KUSKOV, G.N. GORDAN, L.T. EREMEEVA, I.L. BOGAJCHUK and T.V. KAJDA

E.O. Paton Electric Welding Institute, NASU

11 Bozhenko Str., 03680, Kiev, Ukraine. E-mail: office@paton.kiev.ua

\begin{abstract}
Effect of magnetic-pulsed treatment on structure of surfacing filler material, i.e. shot from high-chromium cast iron, was investigated. Effect of magnetic-pulsed treatment on refining of structure of shot metal, quantitative composition of phases and parameters of their crystal lattice was determined. New properties of the shot received as a result of magnetic-pulsed treatment are not inherited by deposited metal. 5 Ref., 2 Tables, 3 Figures.
\end{abstract}

Keywords: electroslag surfacing, current-carrying mold, shot, deposited metal, magnetic-pulsed treatment

The E.O. Paton Electric Welding Institute developed a method of electroslag surfacing and remelting in current-carrying mold [1]. Compact (large section electrodes - rods, bars, plates; wires, strips etc.), discrete (shot, powder, chip etc.) and liquid surfacing consumables can be used with this method.

Practice and theoretical investigations showed that application of discrete materials is perspective for electroslag process. Shot is the most widespread discrete material, which has found industrial application in surfacing [2]. Its can be produced using different technological schemes [3]. The main condition of possibility of its application as surfacing filler is optimum size and form of granules, their low gas-saturation and high metal density.

Electroslag process as a result of melting of surfacing consumables promotes for formation of liquid metal pool, which on volume is more comparable with pool volume in casting than, for example, with weld pool forming in fusion arc welding. Therefore, number of points referring to behavior of liquid metal in casting can be related to electroslag process with sufficient level of approximation.

In particular, it is referred to determined in casting practice fact of effect of properties of charge materials on properties of liquid metal and, as a result, on quality of produced castings. This interconnection was termed «inheritance» and now present research direction is actively developed by school of V.I. Nikitin and his colleagues [4]. Authors of this direction think that the «guided effect on structure of charge metals can help to caught a response (trace) of structural or another information at different stages of casting production, after passing liquid state» is the main peculiarity of structural inheritance.

Different ways can be used for introduction such information in the charge materials. One of such methods based on classification of V.I. Nikitin is solid-phase treatment, which allows receiving non-equilibrium structures, saturated by dislocations, with thin mosaic structure. Heat treatment, pressure treatment, electrolytic treatment and physical treatment, i.e. magnetic, ultrasonic, laser etc., can be referred to it.

Investigations on evaluation of effect of special treatment of discrete surfacing consumable, i.e. shot, on structural changes of granules as well as deposited metal produced at their melting in slag pool were carried out in present work.

Magnetic-pulsed treatment (MPT) was taken as a method of influence on discrete filler.

Selection of such treatment was caused by the investigations [5], carried in Bauman Moscow State Technical University and Moscow State Mining University, which showed significant increase of efficiency of some traditional methods of strengthening and protection of surfaces of machine parts at additional application of MPT.

\begin{tabular}{|c|c|}
\hline \multirow{2}{*}{\multicolumn{2}{|c|}{$\begin{array}{l}\text { Comparative evaluation of traditional methods } \\
\text { of strengthening of machine parts using MPT, \% }\end{array}$}} \\
\hline & \\
\hline Phosphatizing ... & 120 \\
\hline Chroming ............ & .. 140 \\
\hline 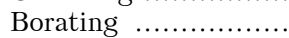 & ... 126 \\
\hline Plasma spraying .... & $\ldots 167$ \\
\hline Diffusion chroming ... & 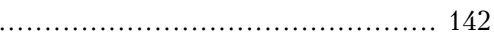 \\
\hline Explosion treatment. & \\
\hline Rolling $\ldots \ldots \ldots \ldots \ldots . . .$. & .. 156 \\
\hline Cold work ............... & 120 \\
\hline
\end{tabular}




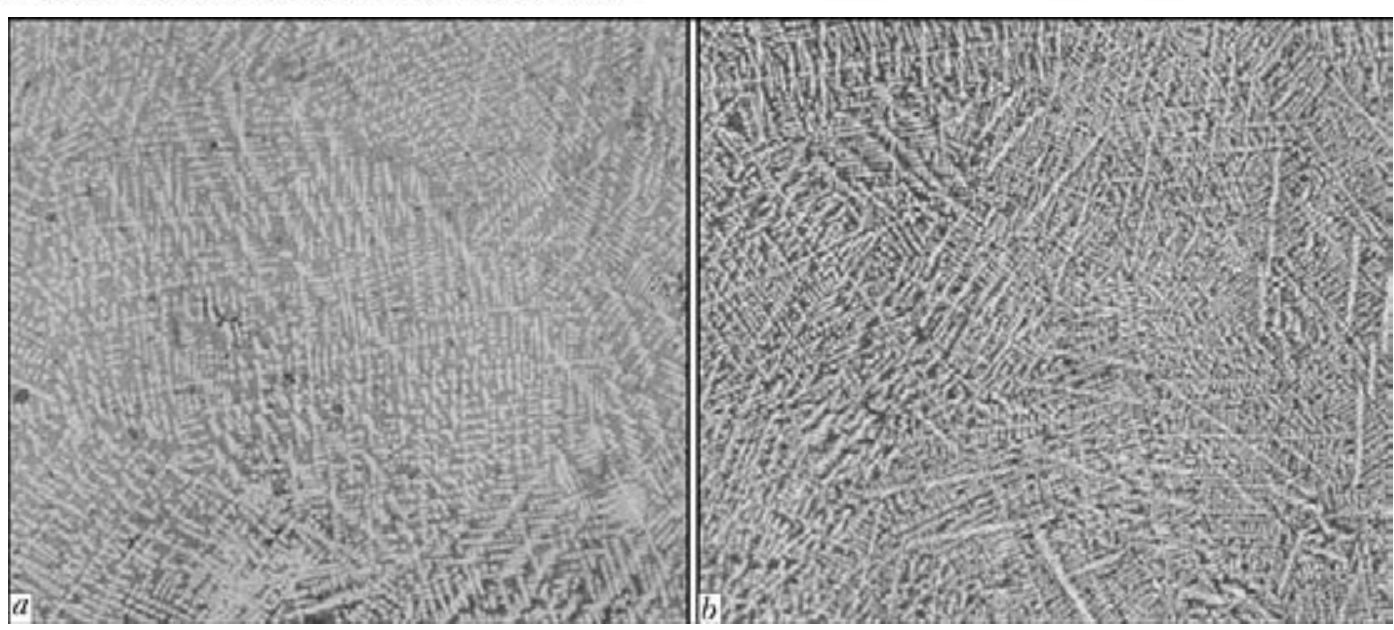

Figure 1. Microstructure $(\times 400)$ of shot metal in initial state $(a)$ and after MPT $(b)$

Isothermal quenching ................................. 136

Step-by-step quenching …....................................... 128

Quenching with cold treatment at $-270{ }^{\circ} \mathrm{C}$............. 150

Thermomechanical treatment .............................. 170

Shot from high-chromium cast iron (25$28 \% \mathrm{Cr}$ ), produced by air spraying of jet of liquid metal [3], was used for surfacing in currentcarrying mold of $180 \mathrm{~mm}$ diameter. Fractional composition of shot was $0.8-2.5 \mathrm{~mm}$. Surfacing was carried out using two batches of shot, namely one untreated, and the second was subjected to MPT using Moscow State Mining University technology* Technological parameters of surfacing in both cases were similar.

Shots of both batches as well as deposited metal, produced with their application, were examined with the help of optical metallography, $\mathrm{X}$-ray spectrum and X-ray structural analysis.

The following equipment was used: X-ray spectrum analysis - Camebax SX-50; X-ray structural analysis - DRON Um-1; optical metallography - Neophot-32 and Versamet microscopes; and LECO hardness meter H-400.

Results of metallographic investigations of shot metal. Metallographic examinations and MXSA determined that shots, treated by MPT as well as not treated, have dendrite structure. The dendrites were formed by austenite grains, and martensite constituent of the structure was

Table 1. Phase composition and parameters of crystal lattices of shot metal in initial state and after MPT

\begin{tabular}{|c|c|c|c|c|}
\hline \multirow{2}{*}{ Phase } & \multicolumn{2}{|c|}{ Without MPT } & \multicolumn{2}{|c|}{ After MPT } \\
\hline & wt. $\%$ & parameter, $\AA$ & wt.\% & parameter, $\AA$ \\
\hline Austenite & 69.74 & $a: 3.6253$ & 53.49 & $a: 3.6126$ \\
\hline Martensite & 29.31 & $\begin{array}{l}a: 2.8976 \\
c: 2.9092\end{array}$ & 45.51 & $\begin{array}{l}a: 2.8967 \\
c: 2.9043\end{array}$ \\
\hline
\end{tabular}

\footnotetext{
${ }^{*}$ MPT was carried out under the leadership of Dr. V.G. Ivakhnik.
}

located interdendritic space. MPT treatment results in refining of shot metal structure on average by $50 \%$ (Figure 1). It follows from visual evaluation as well as measurement of dendrite parameter (distance between the axes of the second order was 7.59 and $4 \mu \mathrm{m}$, respectively), performed by linear method using Versamet microscope. Some difference is observed in indices of microhardness of untreated and treated metal (HV0.1-5500 and $5960 \mathrm{MPa}$, respectively). Distribution of alloying elements over shot section and their metal chemical composition before and after treatment remain virtually unchanged.

$\mathrm{X}$-ray structural analysis allowed determining quantitative composition of phases of metal of surfacing filler before and after its treatment by MPT, as well as calculating parameters of their crystal lattices. According to received results MPT gave rise to change of these indices ( $\mathrm{Ta}-$ ble 1).

Results of examination of deposited metal. Microstructure of metal, deposited using both types of shot, represents itself austenite matrix with carbides $(\mathrm{CrFe})_{7} \mathrm{C}_{3}$ located in it at longitudinal as well as transverse directions, and chromium-carbide eutectics (Figure 2).

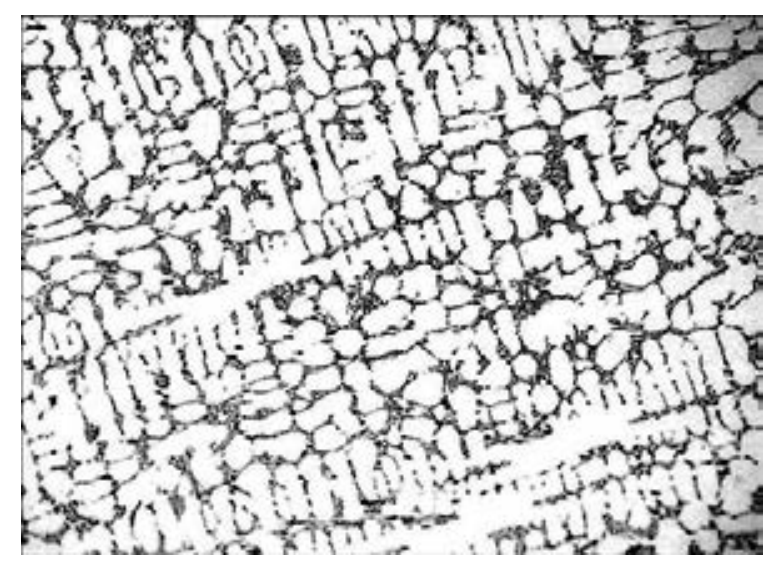

Figure 2. Microstructure $(\times 200)$ of deposited high-chromium cast iron 
Table 2. Phase composition of metal, deposited by untreated and MP-treated

\begin{tabular}{||l|c|c|}
\hline \multirow{2}{*}{\multicolumn{1}{|c|}{ Phase }} & Without MPT & After MPT \\
\cline { 2 - 3 } & wt.\% & wt.\% \\
\hline$\gamma$-Fe & 65.63 & 66.54 \\
\hline$\alpha-\mathrm{Fe}$ & 20.97 & 22.80 \\
\hline Carbide $(\mathrm{CrFe})_{7} \mathrm{C}_{3}$ & 13.40 & 10.65 \\
\hline
\end{tabular}

Distribution of alloying elements (Figure 3) and phase composition (Table 2) of metal, deposited by shot, in initial condition and after MPT does not virtually change.

Thus, though magnetic-pulsed treatment changes for better the properties of discrete surfacing filler in form of shot, but these changes are not preserved in the deposited metal.

It is seems that metal, which has passed temperature of Curie point and being further melted, loses all positive changes determined by magnetic effect on filler metal. It should be noted that earlier work [4] represented magnetic treatment of charge as theoretically possible without verification of positive effect of this method on charge at casting of real products. Obtained examination results allowed recommending MPT for deposited metal. Relevance of such technological solution is justified by investigations carried in work [5].

\section{Conclusions}

1. It is determined that MPT allows significant changing of properties of surfacing discrete filler, but these changes are not preserved in the deposited metal.

2. It can be interesting to investigate other methods (not magnetic ones) of effect on filler in order to improve deposited metal quality.
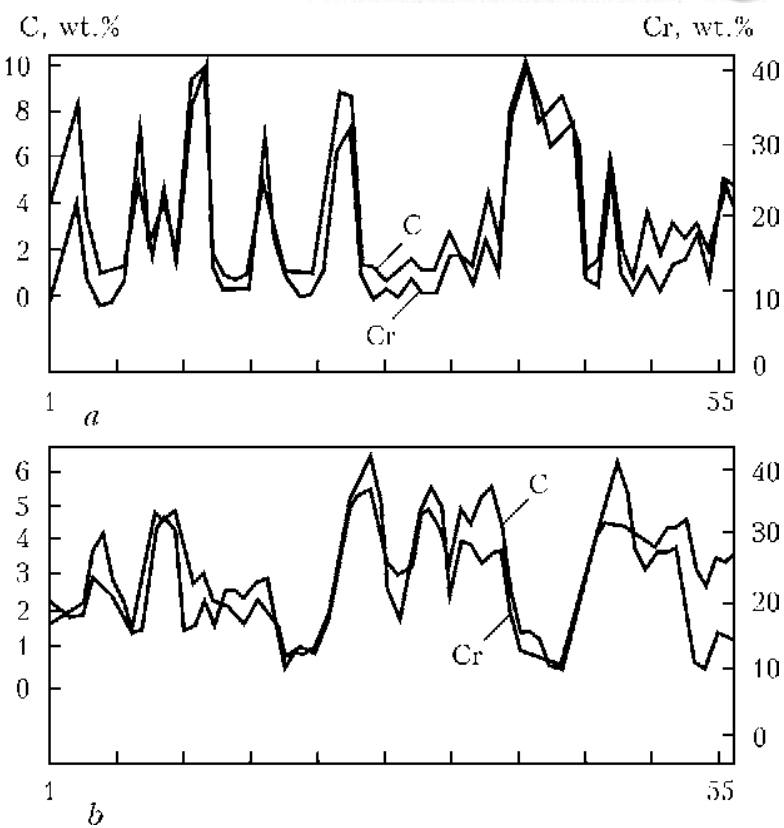

Figure 3. Distribution of chromium and carbon in metal, deposited by shot: $a$ - in initial state; $b-$ subjected to MPT

3. Obtained investigation results allow recommending MPT for deposited metal. Relevance of such technological solution is justified by investigations carried in work [5].

1. Kuskov, Yu.M. (2003) A new approach to electroslag welding. Welding J., 4, 42-45.

2. Ksyondzyk, G.V., Kuskov, Yu.M. (1978) Cast-iron shot - a new type of filler material for electroslag surfacing. In: Theoretical and technological principles of surfacing. Surfacing materials, 80-82. Ed. by I.I. Frumin. Kiev: PWI.

3. Zatulovsky, S.S., Mudruk, L.A. (1988) Production and application of metal shot. Moscow: Metallurgiya.

4. Nikitin, V.I., Nikitin, K.V. (2005) Inheritance in cast alloys. 2nd ed. Moscow: Mashinostroenie.

5. Kantovich, L.I., Malygin, B.V., Pervov, K.M. (2007) Increase in resource of tool and parts of mining machines by magnetic treatment method. Gornoe Oborud. i Elektromekhanika, 1, 13-16.

Received 20.03.2015 